\title{
The cost of treatment of dermatological disorders in hospital versus health centre
}

\author{
ÓLAFUR ÓLAFSSON \\ From the Chief Medical Office of Health for Iceland
}

\author{
EYJÓLFUR HARALDSSON \\ From the Health Centre, Kopavogi
}

SUMMARY Well-run outpatient services and reasonable charges to patients for drugs have led to reduced hospitalisation of dermatological patients and hence a reduction in the total cost of nursing and treating such patients in comparison with previous years, when there was greater emphasis on hospital treatment. There is at present no waiting list for dermatological beds at the National Hospital.

The growing cost of health services has been the subject of some debate. This is understandable in view of the fact that in 1975 Iceland spent some six per cent of its gross national product on health services, discounting all spending on hospital building and the education of health professionals. There has consequently been concern about the relative costs of different forms of treatment. This paper examines the implications of alternative forms of treatment for dermatological patients.

Since 1972, the Office of the Chief Medical Officer of Health and the State Bureau for Drug Control have carried out systematic studies of drug consumption in the Reykjavik area (Grimsson and Ólafsson, 1977; Grimsson et al., 1977; Ólafsson and Grimsson, 1977a; 1977b). Table 1 shows the number of prescriptions, the quantities prescribed, and the costs, for dermatological drugs used by patients not in hospitals from 1972 to 1976 . In 1972, patients paid half the cost of these drugs. Because of complaints from patients about the heavy expenses incurred, since many do indeed need large quantities, the Ministry of Health issued a ruling on 1 February 1974 which permitted the health service to pay the full cost of drugs required by patients certificated as suffering from psoriasis and eczema, provided that they produced the necessary documents. Otherwise the method of paying for these drugs was that laid down in the provisions of an ordinance of 15 June 1974, which required a patient to pay Kr. 260 of the cost of each prescription. As Table 1 shows, the quantity of dermatological drugs prescribed increased by $82 \%$ between 1972 and 1976 , and costs rose by $82.7 \%$ (after correcting for price increases and the rise in the cost of living index during that period). Thus the increased annual expenditure by the health service was $\mathrm{Kr} .16$ million. A list of the drugs prescribed is given in Table 2.

Table 1 Dermatological drugs* 1972-76

\begin{tabular}{|c|c|c|c|c|c|}
\hline \multicolumn{2}{|c|}{ No. of prescriptions } & \multicolumn{2}{|c|}{ Quantity (g) } & \multicolumn{2}{|c|}{ Cost $(K r)}$. \\
\hline 1972 & 1976 & 1972 & 1976 & 1972 & 1976 \\
\hline 1461 & 1434 & 44161 & 80418 & 660016 & 3016078 \\
\hline
\end{tabular}

* Group 50 C (Ministry of Health and Social Security, 1975).

Table 2 Types of dermatological drugs prescribed in 1974 and 1976

\begin{tabular}{ll}
\hline 1974 & 1976 \\
\hline Betnovate & Betnovate \\
Cortril & Calmuril \\
Delmesone & Cortril \\
Kenacort & Delmesone \\
Locorten & Kenacort \\
Synalar & Locorten \\
Ultralan & Metosyn \\
& Synalar \\
& Topilar \\
& Trimycin \\
\hline
\end{tabular}

Table 3 Admission to the dermatology ward of the National Hospital 1972-76

\begin{tabular}{|c|c|c|c|}
\hline & 1972 & 1974 & 1976 \\
\hline $\begin{array}{l}\text { No. of patients on waiting list } \\
\text { Mean waiting time (days) }\end{array}$ & $\begin{array}{l}23 \\
23 \cdot 5\end{array}$ & 6 & $\begin{array}{l}1-2 \\
1-2\end{array}$ \\
\hline
\end{tabular}


Concurrently, there was a change in the waiting list of the dermatology ward of the National Hospital (Table 3). The consultant in charge reported that in 1976 there were frequently two or three beds out of the 14 in the ward which were not occupied by dermatological patients.

It should be noted that in 1973 , outpatient services in the Reykjavik area were greatly improved by the opening of an outpatient dermatology clinic at the Kopavogur Medical Centre and another at the Reykjavik Health Centre. Thus access to these services was made easier for patients and attendance at the outpatient clinics markedly increased. Physicians at the Kopavogur Medical Centre say that they have received a large number of patients previously treated for long or short periods in the dermatology ward of the National Hospital. Many of these patients are now in full employment throughout the year.

\section{Conclusion}

The reasons for the changes shown in Table 3 are as follows. Firstly, patients suffering greatly from psoriasis and other dermatological diseases have received drugs free since 1974 , and other patients can purchase these drugs at reasonable prices. So fewer patients than before have needed hospital treatment.
The increase in the cost of drugs prescribed between 1972 and 1976 is equivalent to the cost per annum of about two dermatological beds. Secondly, outpatient services in the Reykjavik area have been considerably increased and attendance at outpatient dermatology clinics has risen greatly each year.

It is therefore our opinion that in spite of the increase in total drug costs, the change has resulted in considerable savings, due to the reduced number of days spent in hospital and to reduced financial assistance to patients who are out of work. A large number of patients have been spared lengthy stays in hospital and long periods of waiting for admission.

Reprints from Ó. Ólafsson, Chief Medical Officer of Health for Iceland, Arnarhuali, Reykjavik, Iceland.

\section{References}

Grimsson, A., and Olafsson, O. (1977). Drug prescription in Iceland. British Journal of Preventive and Social Medicine, 31, 65-66.

Grimsson, A., Idenpaan, J. H., Heikkila, Lunde, P. K., Ólafsson, O., and Westerlund, B. (1977). Forbrukning av psykofarmaka i Finland, Island, Norge och Sverige. Nordisk Medicin, 92, 49-54. Ministry of Health and Social Security (1975). Drugs of Iceland. Ministry of Health and Social Security: Reykjavik.

Olafsson, O., and Grimsson, A. (1977a). Drug use in Reykjavik. Journal of the Icelandic Medical Association, 63, 65-67.

Olafsson, O., and Grimsson, A. (1977b). Consumption of narcotics in Iceland Journal of the Icelandic Medical Association, 63, 3-9. 